\title{
Improved pain relief after thoracotomy: use of cryoprobe and morphine infusion
}

\author{
I A ORR, D J M KEENAN, J W DUNDEE
}

\begin{abstract}
In a randomised controlled trial carried out during the first two days after thoracotomy patients who had had intercostal nerves frozen with a cryoprobe or were given morphine by continuous intravenous infusion had significantly less pain at rest than patients given intramuscular morphine. Differences between the groups with respect to pain on movement and during physiotherapy were not significant. Pain was estimated using visual analogue scales, and an arc sine transformation was carried out on values obtained from these scales before comparison using an analysis of variance. The trial did not distinguish between the cryoprobe and infusion treatments.
\end{abstract}

The simplicity of the cryoprobe had much to commend it, but in units without access to this equipment a small infusion pump offers a satisfactory alternative.

\section{Introduction}

Thoracotomy is one of the most painful surgical incisions, ${ }^{12}$ and current analgesic techniques rarely provide satisfactory pain relief without unacceptable side effects. Totally effective bolus doses of opioids may cause respiratory depression, ${ }^{3}$ and epidural analgesia with local anaesthetics may cause unacceptable hypotension ${ }^{4}$ and weakening of respiratory muscles. Both epidural and paravertebral administration of local anaesthetics require intensive nursing care, which may not be routinely available in some centres where thoracotomy is carried out. ${ }^{4}$ Other and more promising forms of pain relief include using a cryoprobe during thoracotomy $y^{5-7}$ and a continuous intravenous infusion of

Department of Anaesthetics, Queen's University of Belfast, Belfast BT9 7BL

I A ORR, FFARCS(I), DRCOG, research fellow

J W DUNDEE, PHD, FFARCS, professor

Thoracic Surgical Unit, Royal Victoria Hospital, Belfast, Belfast BT12 6BA

D J M KEENAN, MB, FRCS, registrar morphine. ${ }^{8} 9$ A recent report $^{7}$ was particularly enthusiastic about the cryoprobe but did not make a direct comparison with different methods. This study is a direct comparison of the cryoprobe and morphine infusion techniques with a recognised standard method of pain relief after thoracotomy.

\section{Patients and methods}

We studied 45 patients aged 25-70 years who conformed to grades 1-3 of physical fitness ${ }^{10}$ and were scheduled for thoracic surgery on a morning operating list. The patients gave informed consent and were randomly divided into three groups of 15-a control group, a cryoprobe group, and a morphine-infusion group. The method of estimating pain using visual analogue scales was explained.

\section{TECHNIQUE}

Premedication was with a non-opioid, either diazepam or meprobamate. In the anaesthetic room morphine was administered intravenously using a dose scale $40-60 \mathrm{~kg}, 7.5 \mathrm{mg} ; 60-80 \mathrm{~kg}, 10 \mathrm{mg}$; and $80-100 \mathrm{~kg}, 12.5 \mathrm{mg}$. Anaesthesia was with thiopentone or alphadolonealphaxalone, pancuronium, and nitrous oxide-oxygen-enflurane mixture administered through a Robertshaw double-lumen tube by intermittent positive-pressure ventilation. The control and infusion groups had five or six intercostal nerves anaesthetised with $0.5 \%$ bupivacaine (five nerves round the incision site, the sixth at the intercostal drains site if this was beyond the spaces already anaesthetised), and in the cryoprobe group the same nerves were exposed by sharp dissection and frozen with a cryoprobe (Spembly Ltd, Andover, Hants) applied for 45 seconds followed by a five-second thaw. The freezing procedure, including isolation of the nerve, took about 10 minutes in patients with normal pleurae. Myoneural block was reversed with a standard weight-related neostigmine-atropine mixture. All patients breathed humidified oxygen in the first 24 hours after recovery. When analgesia was requested in the recovery ward this was provided with intravenous morphine administered by slow titration until the patient was satisfied with pain relief, drowsiness supervened, or a dose of $20 \mathrm{mg}$ had been given. Thereafter analgesia in the control and cryoprobe groups was achieved with intramuscular morphine given on request in the same dose range as that used at induction of anaesthesia.

In the infusion group, after the titration dose, a morphine infusion was begun on the scale $40-60 \mathrm{~kg}, 1 \mathrm{mg} / \mathrm{h} ; 60-80 \mathrm{~kg}, 1.25 \mathrm{mg} / \mathrm{h}$; and $80-100 \mathrm{~kg}, 1.5 \mathrm{mg} / \mathrm{h}$. The rate was reduced by $25 \%$ for patients over 
60. If no titration dose was requested the infusion was begun 30 minutes after recovery to the extent of being able to give date of birth If the nurse in charge thought that analgesia was very inadequate and advice was not immediately available she could give morphine $5 \mathrm{mg}$ intramuscularly, but otherwise she was asked to increase the infusion rate after consultation. Similarly if she thought that the patient was becoming unacceptably unresponsive the infusion could be stopped and restarted later at a lower rate. The infusion was discontinued at 1200 on the first postoperative day and analgesia thereafter given on request by the intramuscular regimen. One medical observer was responsible for all analgesic titrations, adjustment of infusion rates, and other probiems of pain relief.

\section{MEASUREMENT}

Severity of pain was graded by the patients on a $10 \mathrm{~cm}$ visual analogue chart ${ }^{11}$ (top end, most severe pain imaginable; bottom end, no pain at all), one mark representing pain at rest and one the pain on moving and breathing deeply. For clarity the distance of each mark in $\mathrm{mm}$ from the bottom of the chart is referred to here as a pain score.

Physiotherapy was carried out on four occasions. Patients graded the pain of this procedure on visual analogue scales and physiotherapists recorded their opinions of the patients' ability to cough on a five-point scale (1, very good; 2 , good; 3 , fair; 4, poor; 5 , none). Staff nurses also graded their subjective impressions of the patients comfort during four time periods on visual analogue scales (top end, "I thought the patient was very comfortable during the period he was under my care"; bottom end, "I thought the patient was very uncomfortable during the period he was under my care"). We did not expect to base firm conclusions on these subjective data, but it was a genuine attempt to quantify opinions of the staff most closely concerned with the patients in the early postoperative period. Patients in the control and cryoprobe groups were unaware of differences in treatment, as were nurses and physiotherapists. Patients in the infusion group became aware that they were receiving pain relief by an infusion only when they requested further analgesia and the infusion rate had to be increased.

\section{STATISTICAL METHODS}

A normal distribution of pain scores may not be possible, as the visual analogue scale is constrained by finite ends, and an arc sine (root) transformation was therefore carried out on pain scores. ${ }^{12}$ Continuous analysis of variance was used to study the effect of treatment and time on differences between pain scores obtained seven times between three hours after recovery and 1200 on the second postoperative day. A single analysis of variance was used to study the effect of treatment 90 minutes after recovery and on the eighth day. The number of requests for analgesia made by the control and cryoprobe groups was compared by the Mann-Whitney $U$ test. Subjective data relating to nurses' and physiotherapists' opinions were not submitted to statistical analysis but are presented in graphical or tabular form. Average pain scores are presented graphically for comparison with other studies but statistical results apply to transformed values, not the simple averages. The computer package used accounted for missing values. A total of seven out of 990 possible values were used in the statistical analysis.

\section{Results}

Table I gives the physical characteristics of patients in the three groups. The continuous analysis of variance carried out on transformed scores obtained between three hours after recovery and 1200 on the second postoperative day showed that both the infusion and cryoprobe groups had significantly less pain at rest than the control group but did not differ from each other $(F(2,42)=7 \cdot 76 ; p=0.001)$ (fig 1). There was no interaction of time with treatment, implying that the relative effectiveness of the three treatments was comparable at all times. Pain at rest decreased consistently with time in all groups $(\mathrm{F}(6,252)=10.31 ; \mathrm{p}<0.001)$.

Differences between groups with respect to pain on movement were not significant $(F(2,42)=2 \cdot 60 ; p=0.08)$ (fig 2). There was no interaction of time with treatment. Pain on movement remained consistently high during the first 24 hours after operation but was significantly reduced by the second day $(F(6,252)=2.72 ; p=0.01)$.

Differences between groups with respect to pain of physiotherapy
TABLE I-Physical characteristics and analgesic requirements of patients in three study groups

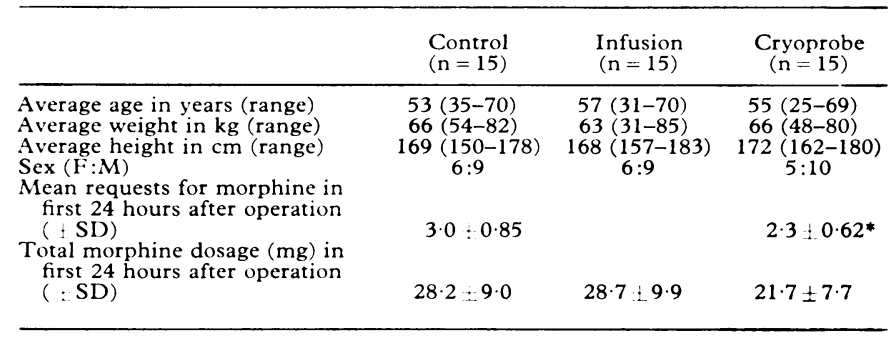

${ }^{*} \mathrm{p}=0.02$.

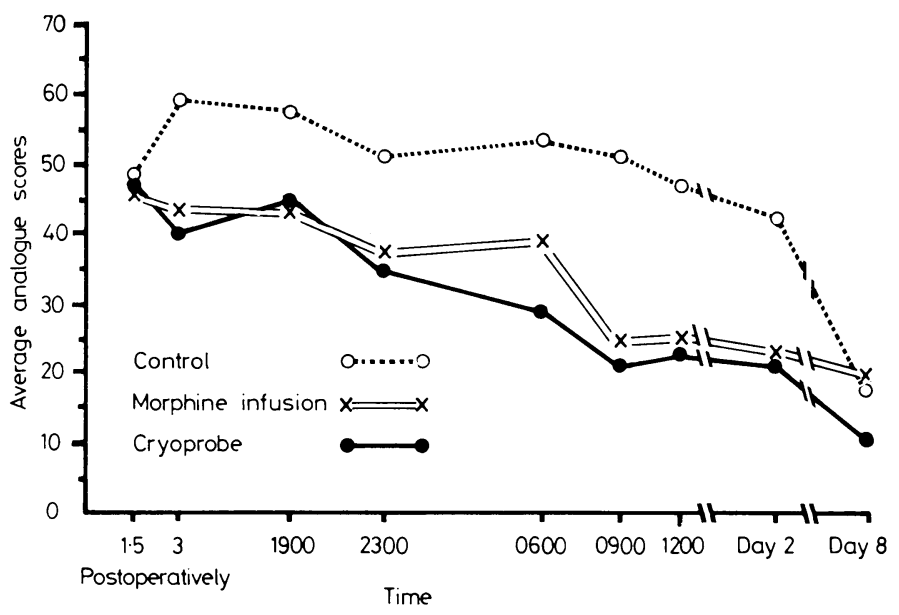

FIG 1 -Changes in average pain scores at rest during study.

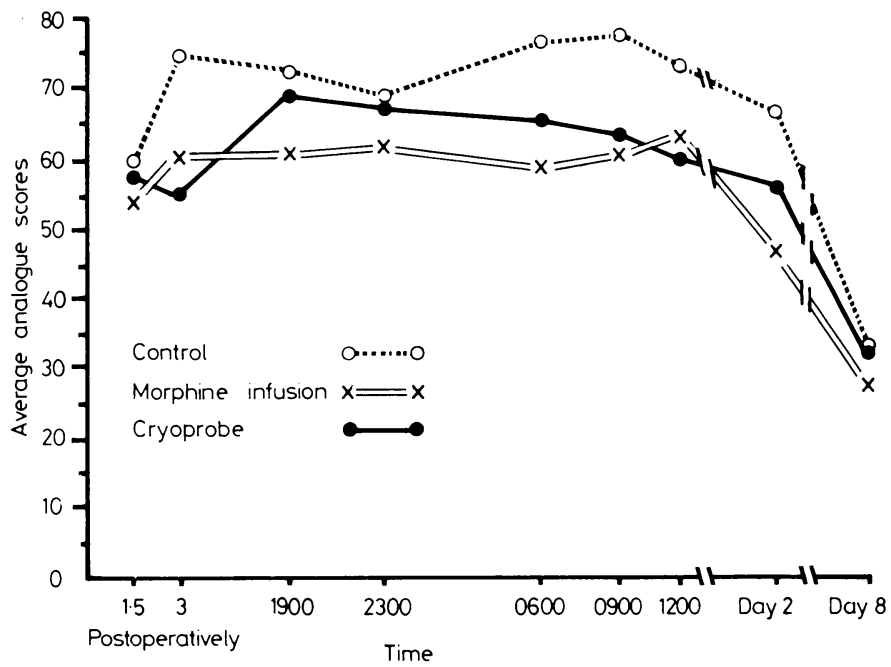

FIG 2-Changes in average pain scores on moving during study.

were not significant $(F(2,42)=1.61 ; p=0.21)$ (fig 3 ). There was no interaction of time with treatment and there was no change in pain of physiotherapy with time.

Single analysis of variance of transformed scores for pain both at rest and on movement 90 minutes after recovery showed no differences between the groups. This was to be expected, as the effect of the bupivacaine intercostal nerve block was unlikely to have worn off at that stage, and each group had had broadly similar analgesic treatment. This tended to confirm the initial comparability of the groups.

The number of requests for analgesia made by patients during the first 24 hours was significantly less in the cryoprobe group than in the control group $(p=0.02)$. The average total dose of morphine in the control and infusion groups was similar.

Subjective opinions of the trained staff nurses and of the physio- 


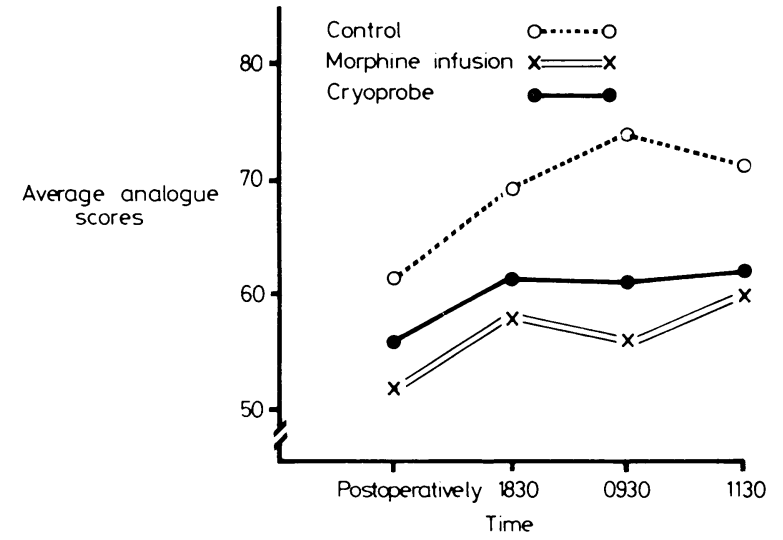

FIG 3-Changes in average pain scores related to physiotherapy during study.

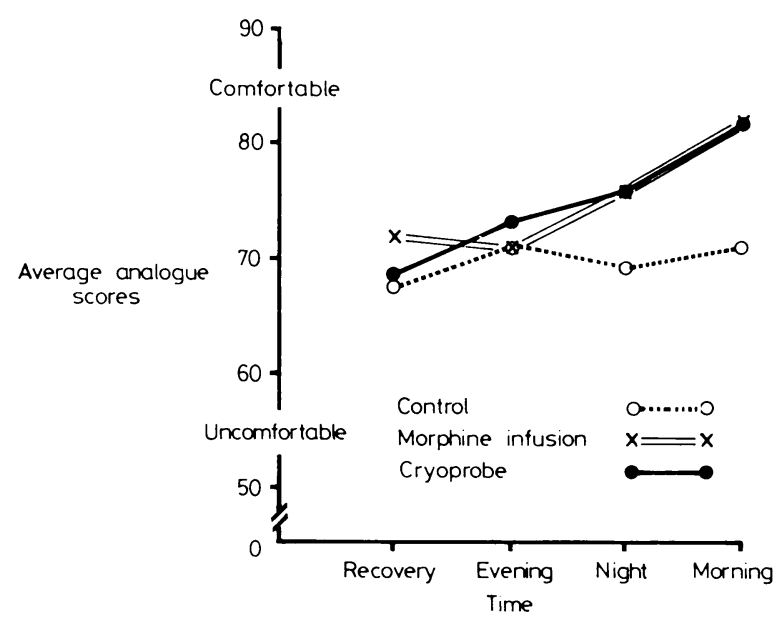

FIG 4-Changes in nurses' subjective estimation of patient comfort during study.

TABLE II-Physiotherapists' opinions of attempts at coughing by patients in the three groups

\begin{tabular}{lccc}
\hline \multirow{2}{*}{ Time } & \multicolumn{3}{c}{ No of scores better than 3} \\
\cline { 2 - 4 } & Control & Infusion & Cryoprobe \\
\hline Postoperatively & 2 & 5 & 2 \\
1830 & 2 & 2 & 3 \\
0930 & 4 & 2 & 5 \\
1130 & 2 & 6 & 6 \\
\hline Total & 10 & 15 & 16 \\
\hline
\end{tabular}

TABLE $\mathrm{III}-$ Average respiratory rate/min during first 24 hours

\begin{tabular}{|c|c|c|c|c|c|c|c|}
\hline \multirow{2}{*}{ Group } & \multicolumn{2}{|c|}{$\begin{array}{c}\text { Hours after } \\
\text { operation }\end{array}$} & \multicolumn{5}{|c|}{ Absolute time } \\
\hline & 1.5 & 3 & 1900 & 2300 & 0600 & 0900 & 1200 \\
\hline $\begin{array}{l}\text { Control } \\
\text { Infusion } \\
\text { Cryoprobe }\end{array}$ & $\begin{array}{l}22 \\
21 \\
21\end{array}$ & $\begin{array}{l}22 \\
22 \\
22\end{array}$ & $\begin{array}{l}24 \\
22 \\
22\end{array}$ & $\begin{array}{l}24 \\
22 \\
22\end{array}$ & $\begin{array}{l}25 \\
22 \\
22\end{array}$ & $\begin{array}{l}23 \\
22 \\
22\end{array}$ & $\begin{array}{l}24 \\
22 \\
22\end{array}$ \\
\hline
\end{tabular}

TABLE IV-Average blood pressure during first 24 hours (to $5 \mathrm{~mm} \mathrm{Hg}$ )

\begin{tabular}{|c|c|c|c|c|c|c|c|}
\hline \multirow{2}{*}{ Group } & \multicolumn{2}{|c|}{$\begin{array}{l}\text { Hours after } \\
\text { operation }\end{array}$} & \multicolumn{5}{|c|}{ Absolute time } \\
\hline & 1.5 & 3 & 1900 & 2300 & 0600 & 0900 & 1200 \\
\hline $\begin{array}{l}\text { Control } \\
\text { Infusion } \\
\text { Cryoprobe }\end{array}$ & $\begin{array}{l}115 / 70 \\
125 / 75 \\
125 / 75\end{array}$ & $\begin{array}{l}125 / 70 \\
130 / 70 \\
125 / 70\end{array}$ & $\begin{array}{l}125 / 75 \\
130 / 80 \\
130 / 80\end{array}$ & $\begin{array}{l}125 / 75 \\
125 / 75 \\
130 / 75\end{array}$ & $\begin{array}{l}120 / 75 \\
125 / 75 \\
125 / 75\end{array}$ & $\begin{array}{l}110 / 70 \\
125 / 75 \\
125 / 75\end{array}$ & $\begin{array}{l}115 / 75 \\
125 / 75 \\
125 / 75\end{array}$ \\
\hline
\end{tabular}

therapists were consistent with the infusion and cryoprobe groups having better analgesia than the controls (fig 4; table II). Vital signs did not differ significantly between groups (tables III and IV).

Single analysis of variance of transformed scores for pain both at rest and on movement on the eighth day showed no differences between the groups, despite the continued presence of loss of pinprick sensation round the wound in the cryoprobe group.

Nurses found the morphine infusions relatively easy to manage. Five patients in the infusion group were judged to require an intramuscular injection of morphine as well as an increase in the infusion rate. This was usually three to four hours after operation, probably when the effect of the bupivacaine intercostal nerve block was wearing off. Three patients had to have the infusion stopped and restarted at a lower rate. In one case, where doxapram was given, this was thought to be due to a combination of postanaesthetic drowsiness and a relatively excessive titration dose of morphine. A second case was thought to have occurred when a drip through which the infusion was running became occluded and subsequent resiting allowed morphine which had accumulated in the drip tubing to be flushed into the patient. After this episode house officers were requested to flush the drip tubing before resiting cannulae. There was no evidence of the infusion group as a whole being overdrowsy, as shown by their ability to co-operate with nursing procedures.

One patient in the control group had the dosage of further intramuscular boluses reduced when he became drowsy and his respiratory rate dropped to eight per minute 40 minutes after an intramuscular dose.

\section{Discussion}

Cryotherapy depends on the ability of extreme cold (less than $-20^{\circ} \mathrm{C}$ ) to cause degeneration of nerve axons without destroying the sheath architecture, thus allowing the axons to regrow steadily over a period of months. ${ }^{13}$ Unfortunately the pain of thoracotomy comes from several diverse sources. Freezing intercostal nerves will reduce incisional pain, though part of the skin incised will be supplied by the dorsal primary rami. Pain from the parietal pleura should be reduced if the intercostal nerve can be frozen proximal to the branching of the collateral intercostal nerve, which is generally the case, though the apical drain will irritate unfrozen segments of the pleura. The visceral pleura is supplied by autonomic nerve fibres. Perhaps the most severe pain complained of after cryotherapy is back pain due to ligamentous strain after rib retraction. The concept of carrying out a freeze which is reversible in the first month ${ }^{6}$ is interesting, but it remains to be shown if this technique can be reliably reproduced.

The use of opioid infusions has gained popularity during the past decade. ${ }^{8} 14$ By preventing really severe pain building up we have shown that a similar total dose of morphine can result in improved pain scores when morphine is infused rather than given in bolus doses. High doses of opioids such as those used by Catling et $a l^{15}$ were not found to be necessary for the infusion technique; it seems logical to adjust the infusion rate to suit each patient ${ }^{8}$ rather than continue with a rate fixed in the recovery ward. Having shown improvement compared with conventional treatment, we are now investigating whether further improvement can be gained by combining the infusion and cryoprobe treatments.

We thank $\mathrm{Mr} \mathrm{H}$ M Stevenson and Mr J Gibbons for permission to study their patients, and $\mathrm{Mr} \mathrm{C}$ Patterson for valuable statistical advice. Thanks are also due to the nursing, physiotherapy, and junior medical staff for their help, and to anaesthetic colleagues for altering their technique. During this study Dr I A Orr was in receipt of a Royal Victoria Hospital (Belfast) fellowship.

\section{References}

${ }^{1}$ Papper E, Brodie BB, Rovenstine EA. Postoperative pain: its use in the comparative evaluation of analgesics. Surgery $1952 ; 32: 107-9$.

${ }^{2}$ Loan WB, Dundee JW. The clinical assessment of pain. Practitioner 1967; 198:759-68. 
3 Jaffe JW, Martin WR. Opioid analgesics and antagonists. In: Gilman AG, Goodman LS, Gilman A, eds. The pharmacological basis of therapeutics. 6th ed. New York: Macmillan, 1980:494-535.

4 Griffith DPG, Diamond AW, Cameron JD. Postoperative epidural analgesia following thoracic surgery: a feasibility study. $\mathrm{Br} \mathcal{F}$ Anaesth $1975 ; 47: 48-55$.

${ }^{5}$ Nelson KM, Vincent RG, Bourke RS, et al. Intraoperative intercostal nerve freezing to prevent post-thoracotomy pain. Ann Thorac Surg $1974 ; 18: 280-5$.

${ }^{6}$ Katz J, Nelson W, Forest R, Bruce DL. Cryoanalgesia for postthoracotomy pain. Lancet $1980 ; \mathrm{i}: 512-3$.

7 Maiwand O, Makey AR. Cryoanalgesia for relief of pain after thoracotomy. Br Med F 1981 ;282:1749-50.

${ }^{8}$ Nayman J. Measurement and control of postoperative pain. Ann R Coll Surg Engl 1979;61:419-26.

${ }^{9}$ Rutter PC, Murphy F, Dudley HAF. Morphine: controlled trial of different methods of administration for postoperative pain relief. $\mathrm{Br}$ Med f $1980 ; 280: 12-3$.

110 American Society of Anesthesiologists. New classification of physical status. Anesthesiology 1963;24:111.

${ }^{11}$ Huskisson EC. Measurement of pain. Lancet 1974 ;ii:1127-31.

12 Aitken RCB. A growing edge of measurement of feelings. Proc $R$ Soc Med 1969;62:989-93.

${ }^{13}$ Barnard D. The effects of extreme cold on sensory nerves. Ann R Coll Surg Engl 1980;62:180-7.

14 Scott JS. Obstetric analgesia. Am f Obstet Gynecol 1970;106:959-78.

${ }^{15}$ Catling JA, Pinto DM, Jordan C, Jones JG. Respiratory effects of analgesia after cholecystectomy: comparison of continuous and intermittent papaveretum. Br Med F 1980;281:478-80.

(Accepted 5 August 1981)

\section{SHORT REPORTS}

\section{Cerebral ischaemia after nifedipine treatment}

Nifedipine, a calcium antagonist with strong vasodilating effects, is particularly effective in the treatment of angina pectoris, ${ }^{1}$ chronic cardiac failure, ${ }^{2}$ and systemic hypertension. ${ }^{3}$ A low incidence of side effects has been reported. ${ }^{3}$ Nevertheless, two recent reports draw attention to the risk of pulmonary oedema ${ }^{4}$ and severe hypotension. ${ }^{5}$ We recently observed two patients who developed cerebral ischaemia a few hours after taking nifedipine.

\section{Case reports}

Case 1-A 72-year-old man was admitted to hospital because of abrupt onset of right hemiparesis and aphasia. Ten years before ischaemic heart disease and slight diabetes mellitus had been diagnosed. He was treated with medigoxin $100 \mu \mathrm{g}$, glibenclamide $2.5 \mathrm{mg}$, and phenformin $25 \mathrm{mg}$ daily. An electrocardiogram performed three days before admission showed atrial fibrillation, ectopic sporadic ventricular contractions, incomplete left bundle branch block, left ventricular hypertrophy, and signs of subendocardial ischaemia. For this reason, nifedipine $10 \mathrm{mg}$ three times a day and hydrochlorothiazide $50 \mathrm{mg}$ and amiloride $5 \mathrm{mg}$ daily were added to treatment. On the second day of treatment, two hours after taking a nifedipine tablet, the patient suffered aphasia and right-sided weakness which lasted for a few minutes. The next morning the patient took another nifedipine tablet, and one hour later he developed the same disturbances. On admission to hospital the systemic arterial pressure and the pulse rate were normal and there were no clinical signs of cardiac failure. The neurological examination showed aphasia and right hemiparesis. Findings on electrocardiogram were similar to those previously noted. The chest radiograph showed slight pulmonary congestion and an enlarged heart. An echocardiogram showed left atrial and ventricular enlargement. Computed tomography showed an ischaemic area in the left hemisphere. Ultrasound examination showed no sign of stenosis or occlusion of extracerebral vessels. Two days after admission, the patient improved dramatically, and neurological examination showed no abnormality. Nifedipine treatment was discontinued, and there have been no further episodes in the following months.

Case 2-A 67-year-old woman was admitted to hospital for sudden loss of consciousness. She had long-standing systemic hypertension treated with hydrochlorothiazide $50 \mathrm{mg}$ daily. Some days before admission nifedipine 10 mg three times a day was added to treatment to control hypertension. On the second day of treatment, two hours after taking nifedipine, the patient suddenly lost consciousness. Once awakened she complained of headache, drowsiness, and vertigo. On admission to hospital, systemic arterial pressure was $170 / 100 \mathrm{~mm} \mathrm{Hg}$ and pulse rate $84 / \mathrm{min}$. Neurological examination showed signs of cerebellar dysfunction. Signs of left ventricular hypertrophy and subendocardial ischaemia were present on electrocardiogram. The chest radiograph showed aortosclerosis. Findings on computed tomography were normal. The patient was discharged taking clonidine $150 \mathrm{mg}$ and hydrochlorothiazide $50 \mathrm{mg}$ daily; nifedipine was discontinued. There were no further occurrences during the follow-up.

\section{Comment}

Both our patients presented risk factors for development of cerebrovascular diseases. Nevertheless, the temporal relation between taking the drug and developing the symptoms raises the suspicion that the drug might have contributed to these episades. In our view two possible mechanisms could be implicated: (a) transient severe systemic hypotension (not observed in our patients at admission to hospital); (b) a more effective vasodilating action of the drug on the peripheral resistance vessels rather than on cerebral vessels. Both factors could be the consequences of an unpredictable action of the drug in aged patients. To our knowledge, this is the first report of cerebrovascular disorders during nifedipine treatment. Further reports could indicate whether our observations were coincidental or whether nifedipine could actually precipitate cerebral ischaemia in aged patients with risk factors for cerebrovascular diseases

${ }^{1}$ Hashimoto K, Kimura E, Kobayashi T, eds. New therapy of ischaemic heart disease. 1st international Adalat symposium. Tokyo: University of Tokyo Press, 1974.

- Klugman S, Salvi A, Camerini F. Hacmodynamic effects of nifedipine in heart failure. Br Heart 7 1980;43:440-6.

Olivari M'T, Bartorelli C, Polese A, et al. Treatment of hypertension with nifedipine, a calcium antagonist agent. Circulation 1979;59:1956-62.

- Gillmer DJ, Kark P. Pulmonary oedema precipitated by nifedipine. Br Med $71980 ; 280: 1420$.

Brooks N, Cattel M, Pidgeon J, Balcon R. Unpredictable response to nifedipine in severe cardiac failure. Br Med f 1980;281:1324.

(Accepted 17 fune 1981)

Clinica Neurologica II, University of Milan, 20122 Milan, Italy

E NOBILE-ORAZIO, MD, research fellow

R STERZI, MD, neurologist, research fellow

\section{Hepatitis $B$ infection in glomerulonephritis}

Persistent viral infections are well recognised causes of glomerulonephritis in animals. The only persistent virus infection in man which has been regarded as a common cause of chronic glomerulonephritis is hepatitis B: the prevalence of hepatitis B carriage in reported series of patients with glomerulonephritis has ranged from 0 to $50 \% .{ }^{1}$ The higher figures have important implications for dialysis and transplantation, as well as throwing an interesting light on the cause of glomerulonephritis. We therefore examined the prevalence of markers of hepatitis B infection in patients with glomerulonephritis in Newcastle upon Tyne.

\section{Patients, methods, and results}

From 1976 to 1980 we investigated 158 patients with various types of glomerulonephritis attending the renal clinic at the Royal Victoria Infirmary. One hundred patients with a similar age range and sex distribution who were suffering from other types of renal disease (polycystic kidneys, chronic pyelonephritis, essential hypertension) were studied as controls. The mean age ( $\perp 1$ SD) of the patients with glomerulonephritis was $39+16$ years (range 15-76; 90 men, 68 women) and that of the controls $42 \pm 15$ years 